\title{
Overt and covert: Strategies for building employability skills of vocational education graduates
}

\author{
Cath Jane Fraser ${ }^{1}$, Gerard Duignan ${ }^{2}$, Deb Stewart ${ }^{3}$ and Agustilia Rodrigues ${ }^{4}$ \\ cath.fraser@toiohomai.ac.nz; gerard.duignan@weltec.ac.nz; DStewart@eit.ac.nz; \\ Agustilia.Rodrigues@whitireia.ac.nz \\ Corresponding author: Cath Fraser \\ ${ }^{1}$ Toi Ohomai Institute of Technology, NZ \\ ${ }^{2}$ The Wellington Institute of Technology, Wellington, NZ \\ ${ }^{3}$ Eastern Institute of Technology, NZ \\ ${ }^{4}$ Whitiriea Polytechnic, NZ
}

\begin{abstract}
Knowing how well higher education providers prepare learners for the working world is becoming increasingly important at all programme levels, and this is nowhere more apparent than with vocational education training. Ensuring our learners can hit the ground running and become immediately productive is essential for the relevance, and probably the survival, of New Zealand's Institutes of Technology and Polytechnics (ITPs). Yet while there is much commentary about the challenges of transitions from tertiary study into employment and the 'employability skills gap', there is all too little given to how this is being addressed in teaching. This paper describes the work of an inter-institutional research collaboration into current approaches being used to embed skills that enhance employability. Drawing on a number of frameworks and models, the research team selected ten core attributes: positive attitude, communication, teamwork, self-management, willingness to learn, thinking skills, resilience, innovation, entrepreneurship and cultural competence. The team then identified a range of strategies being used by highly commended teachers to enhance the ten employability skills: firstly, by observing classroom and online practices of 23 selected teachers from participating organisations; and secondly through follow-up interviews with the same teachers. The key takeaway of this research is raised awareness and intentionality of the overt and covert approaches vocational educators are using to enhance the employability of their students.
\end{abstract}

Key words: employability, skills development, vocational education, workplace transition

\section{Introduction}

The higher education sector in New Zealand comprises an array of provision and provider models: universities, institutes of technology and polytechnics (ITPs), private training establishments (PTEs), and wānanga (a publicly owned tertiary institution that provides education in a Māori cultural context). There are also multiple provider agreements where introductory courses and entry level qualifications from one institute receive credits and ensure enrolment in higher level qualifications awarded by another. There are currently 16 ITPS across New Zealand, all autonomous Crown entities (Tertiary Education Commission (TEC), 2018). Various ITPs offer qualifications from foundation studies to Masters, but for most, their core business is in certificates and diplomas, at sub-degree level. ITPs are charged with delivering technical, vocational and professional education across the country, and seen as vital in preparing young people for work as well as supporting adults to retrain in a rapidly changing economy (TEC, 2018, para. 1), and contributing to their local economies and communities. 
It is therefore critical that ITPs ensure their graduates are well prepared for employment, ongoing professional learning and the challenges of an evolving workplace. In Aotearoa New Zealand the Tertiary Education Commission - Te Amorangi Mātauranga Matua (TEC) now seeks evidence of the effectiveness of programmes of study in preparing graduates for industry. The TEC requires ITPs to report on employer and graduate satisfaction, and also measures the value of qualifications to inform study choices through online surveys such as Rate My Qualification (https://myq.co.nz/). Such accountability, alongside the desire to maximise the development of employability skills in our learners, were drivers for the research which informs this paper.

Inspired by a keynote speaker, Professor Shelley Kinash, at the 2016 National Tertiary Learning and Teaching Conference, and the Australian-based research she shared (Kinash, n.d.; Kinash, Crane, Judd, \& Knight, 2016), a group of delegates from a range of regions, disciplines, qualifications and industry sectors, were keen to progress the 'employability skills' conversation. A preliminary overview of the literature related to work readiness and transitions from tertiary study into employment revealed plenty of information about an 'employability skills gap', through numerous studies where employers and industry representatives decry new graduates' lack of 'can-do' attributes (e.g. Fourie \& Clokie, 2013; 2014). Scott (2015) for example notes the distinction between qualification-assured 'competence' (delivering specific job-specific tasks in relatively predictable circumstances), and 'capability' (responsiveness, creativity and the ability to deal with particular circumstances or unexpected events). The latter, Scott contends, is much more important in almost every work role across the nine professions he studied. This employability skills gap is a concern for teachers, institutions and industry; but what appears to be less well traversed in the literature is the issue of how the skills gap is being addressed in the classroom.

Twelve staff members representing seven providers, formed a research team with the intention of interrogating how teachers in the ITP sector were introducing employability skills into their curriculum delivery. Based on the team's collective experience, the project was conceptualised as fitting within, and complementing frameworks and models already being used by, the higher education sector. The focus area of ITP programmes between Levels 3 to 5 appeared to offer a natural fit with the recently launched national set of standards, the Employability Skills Framework (CareersNZ, 2017), which was selected as a benchmark that would make reporting more meaningful to colleagues already familiar with its design. The Employability Skills Framework describes certain skills, which New Zealand and international employers tell us ... are essential for getting and keeping a job (CareersNZ, 2017, para. 1), such as, positive attitude, communication, teamwork, self-management, willingness to learn, thinking skills, resilience. Recognising that this framework is both generic and oriented towards diverse learners (including those who required academic enrichment), the research team decided to incorporate three other attributes, innovation, entrepreneurship and cultural competence, in the criteria, based on a number of international studies of marketable skills (e.g. Gerstein \& Friedman, 2016; Markes, 2006; Sarkar, Overton, Thompson, \& Rayner, 2016; Shivoro, Shalyefu, \& Kadhila, 2017). These 10 selected employability skills were seen as aligning well with a bigger picture of employability skills aimed at preparing learners for employment opportunities 'at the cutting edge', for advanced programmes of study, and for employment in roles which as yet do not exist (Scott, 2015).

The project was guided by the overarching research question: How can teachers in ITPS embed employability skills into their teaching practices?

Key project objectives were to:

- $\quad$ provide qualitative information from good teachers about the overt and covert strategies they used in the classroom to develop learners' work-readiness skills, alongside curriculum content;

- $\quad$ report this in a framework which aligns to national strategies, such as the 'Employability Skills Framework' (Careers NZ, 2017), and large studies of desirable graduate attributes reported in the literature, such as Scott $(2008 ; 2013 ; 2015)$; and 
- produce a compilation of guidelines and strategies for colleagues' immediate use, to be available online through an open source, higher education database.

\section{Literature review}

Recognition of employability as a measure of efficacy in education outcomes escalated in the late 1990s (Lowden, Hall, Elliot, \& Lewin, 2011; McLaughlin, 1995) alongside the idea that employment and serving the economy should be a primary outcome of education (Lees \& Benza, 2015). Like many other western nations, the New Zealand Government adopted the concept of employability skills as a set of behaviours, attitudes, beliefs and unique personal qualities that enable a person to gain and maintain employment (Ministry of Education, n.d.). The Tertiary Education Strategy 2014-2019 (TES) outlines government priorities for tertiary education: of the six priority areas in the strategy, Priority 1 Delivering skills for industry identifies specific areas of skill shortage and also emphasises that tertiary education should support the development of transferable skills that are needed in all workplaces such as communicating well, processing information effectively, thinking logically and critically and adapting to future change (Ministry of Education, 2014, para. 7).

In 2016, the Ministry of Education published the 'Youth and Transition Framework' (TEC, 2016), followed by the 'Employability Skills Framework' (TEC, n.d.), developed by an advisory group including employer and industry representatives, government agencies and education specialists. It is designed for young people preparing for employment and contains seven characteristics: (1) Positive Attitude; (2) Communication; (3) Teamwork; (4) Self-management; (5) Willingness to learn (6) Thinking skills (problem-solving and decision-making; and (7) Resilience. As described in the previous section, the research team employed these seven items, adding three other attributes, innovation, entrepreneurship and cultural competence, as a foundation for observations of teachers in practice.

That this guiding Framework was developed with the input of multiple agencies, including industry, is highly significant. Employer voice is critical to any discussion about employability skills as they are the ones who employ new graduates, and also, are frequently a source of critique about the lacks and gaps in their new employees' skill set (Lees, Anderson, \& Avery, 2015). Chavan and Surve (2014) conducted a survey of Human Resources (HR) managers across more than 20 companies who identified that the most lacking employability skills among newly recruited employees (from most lacking to least) are, Communication ... management/prioritizing ..., self-confidence ... and decision-making ... (p.258). The same study identified the most important employability skills (from most important to least) as Integrity and honesty, problem-solving, teamwork, self-confidence, Communication skills (p.258). Such research clearly evidences a need for more attention to the development of employability skills in a tertiary vocational learning context.

A recent UK study which focussed on students as stakeholders (Lees et al., 2015) concluded that there is a need to reorient student perspectives on employability to encompass a conception which encourages self-reflection and self-development rather than simply viewing the concept as an object they possess upon graduation (p. 257). In applying a lens offered by Vygotsky's zone of proximal development, it becomes clear that working with learners to understand their perception of employability skills is where teaching should start (Lievens \& Wesseling, 2015). The focus on learner understanding suggests that the notion of including employability skills in teaching should be made explicit, or overt, in order to inform students about these critical factors for success in employment.

In most courses, employability skills are seen as distinct from the subject matter being taught. At many institutions, employability skills appear in the graduate profile, whereas the subject matter appears in the course learning outcomes where they form the focus of the course work and assessment. Gerstein and Friedman (2016) criticise this practice of focusing on learning outcomes that shape hard skills - taught skills which are generally quantifiable and specific to each job - when the rapidly changing (USA) labour market has a heightened need for 
disciplinary knowledge plus (employability) skills (p. 114). What is needed instead, suggest Green and Blaszczynski (2012) is to join the three $R$ 's - reading, writing, and arithmetic with the four C's - creativity, collaboration, communication, and creative thinking (p. 4).

The four C's are examples of soft skills - non-measurable, subjective or self-developed skills that are not specific to one job or career (Hendarman \& Tjakraatmadja, 2012), or what Messum, Wilkes, Peters and Jackson (2016) call generic skills (p. 1). Most commentators concur that soft skill development should be a continuous process throughout the curriculum rather than a 'bolted-on' or 'one shot' approach. As McEwen (2010) asserted, soft skills cannot be taught independent of other subject matter but must be regularly integrated into the lessons [and] consistently reinforced (p. 152). In summary, employability skills deserve their place in the classroom; their teaching needs to be visible and it needs to be integrated.

How is this best achieved? Cranmer (2006) describes three methods of delivering employability skills, two of which have an apparently low impact on the effectiveness on the curriculum and one which appears to have high impact. The methods are:

- 'Total embedding', in which the skills themselves are not made explicit although they are taught. The risk is that the skills become lost in the context - the skills are modelled but not examined (low impact);

- 'Parallel development' where employability skills are taught in separate courses, which makes it difficult to contextualise the skills (low impact); and

- Explicit embedding and integration in which the skills are taught and made overt, including being assessed (high-impact) (Cranmer, 2006; Green \& Blaszczynski, 2012).

Another way of looking at choices in delivery options is through the lens of the "hidden curriculum' which involves the promulgation of often unarticulated and unacknowledged concepts that are never fully explained in class. The debate has both its enthusiasts, and its detractors. For example, students might be working in teams to complete a task, and the focus of the teaching and the assessment is entirely on the content of the task rather than on the process of working in the team. If the teacher does not announce that working in a team is important and it is part of the curriculum, and allocate marks, then the students are unlikely to pay attention to it as part of the learning (Bedwell, Fiore, \& Salas, 2014). Yet advocates of subconscious, or 'covert' learning argue positive influences, in the socio-cultural modelling which occurs, normalising a deliberately fostered culture or way of interacting that can shape future behaviours (Alsubaie, 2015). Putting this conceptualisation into practice, graduates would take their experience of working in groups out into the workplace, with a more or less instinctive feel about how to manage peer relationships, group dynamics, and teamwork roles.

Discussions of group work are, in fact, endemic in the literature. For example, Green and Blaszczynski (2012) describe a series of mostly group-based learning activities that can help students develop employability skills, and that can be adapted to a number of contexts. For these authors, embedding employability skills needs to be a conscious act on the part of the teacher, and the learning of employability skills needs to be a conscious act on the part of the learner. Aside from group work, there are numerous other learning approaches well suited to developing employability skills in context with technical skills. These include responsible learning, experiential/authentic learning, cooperative learning and reflective learning (Kemmis \& Hodge, 2014). Elements of each of these approaches were evident in the data, and informed the project outputs.

\section{Data collection and methodology}

A mixed method, case study methodology was adopted for this research. Case studies allow an in-depth examination of topics over time, related to processes and practice (Schneider, LoBondio-Wood, \& Haber, 2003), and for the purposes of this study, was particularly useful for gathering evidence of how employability skills were being taught in the classroom, and why teachers had adopted their selected approach. 
The participants included 23 experienced teachers, evenly spread across each of the seven participating institutions, and invited to participate by personal contact from each of the researchers. Selection criteria included participants being known by project team members for their good teaching practice, having strong relationships with their employer stakeholder groups, reporting good employment outcomes of their graduates, or having been recognised by the organisation with internal awards or commendations as effective teachers with a strong pedagogical practice. Care was taken to ensure as wide a range of disciplines as possible, such as plumbing, nursing, science, accounting, patisserie, electrical, music technology, seafaring, business administration, counselling and Te reo Māori (Māori language). Participants were also drawn from a range of demographic categories, aiming for a broadly applicable cross-representation of teaching staff. However it is acknowledged that despite these efforts at achieving a diverse participant profile, the study findings, like those of any qualitative study (Ishak \& Bakar, 2013), cannot be generalized to the wider higher education, or even ITP population.

Ethics approval was gained from each of the seven organisations: Wellington Institute of Technology; Whitireia NZ; Toi Ohomai Institute of Technology; Eastern Institute of Technology; Waikato Institute of Technology; Nelson Marlborough Institute of Technology; Taratahi Agricultural Training Centre. Further demographic details are shown in Table 1.

Table 1: Study participants $(n=23)$

\begin{tabular}{|c|c|c|c|c|}
\hline \multicolumn{5}{|c|}{ Years teaching experience } \\
\hline$<5$ & $5-10$ & $11-20$ & $>20$ & \\
\hline 4 & 9 & 4 & 6 & \\
\hline \multicolumn{5}{|c|}{ Employment status } \\
\hline full-time & part-time & & & \\
\hline 22 & 1 & & & \\
\hline \multicolumn{5}{|l|}{ Age } \\
\hline$<25$ & $25-44$ & $45-54$ & $55-64$ & $65+$ \\
\hline 0 & 9 & 6 & 5 & 3 \\
\hline \multicolumn{5}{|c|}{ Teaching sessions observed by qualification level } \\
\hline Level 3 & Level 4 & Level 5 & & \\
\hline 7 & 8 & 8 & & \\
\hline \multicolumn{5}{|c|}{ Duration of teaching session observed } \\
\hline 60 minutes & 90 mins & 120 mins & & \\
\hline 20 & 2 & 1 & & \\
\hline \multicolumn{5}{|l|}{ Ethnic group } \\
\hline NZ European & Māori & Pasifika & Asian & \\
\hline 17 & 3 & 1 & 2 & \\
\hline
\end{tabular}

Data collection involved two phases: first, a classroom observation with each participant, using a standardised form with a template of the ten employability skills the research team were monitoring. The focus was on identifying strategies and moments when the teacher was embedding skills to enhance employability - whether overt or covert - that is, whether the connection with employment and the workplace was explicitly stated, or not. Observed teaching strategies noted by the researcher in the class were sometimes planned and sometimes spontaneous, in response to learners' comments or behaviours.

The second phase involved an interview with the teacher by the researcher-observer, using a semi-structured questionnaire to investigate the teacher's understanding and ideas about how they embed employability skills into their teaching. An initial pilot of the observation/interview process with two colleagues identified the need for an extended descriptor for each of the ten 
skills being monitored, which was developed through collaborative team discussions, and shaped by definitions in the wider literature reviewed, and in particular, the work of Fourie and Clokie (2013; 2014), Gerstein and Friedman (2016), Kemmis et al. (2014), Scott (2013; 2014) and Scott, Coates and Anderson (2008). These descriptors (Table 2) were subsequently tabled as part of the interviews and referred to when necessary to ensure the researcherobserver and the teacher-participant shared a similar understanding of the skill under discussion.

\section{Table 2: The Ten Employability Skills}

\begin{tabular}{ll}
\hline Employability skill & Descriptor \\
\hline Positive attitude & $\begin{array}{l}\text { Having a 'can do' attitude; being optimistic; being honest; being } \\
\text { friendly and showing respect; demonstrating motivation to work hard } \\
\text { taking initiative; ethical integrity; self-confidence; professionalism. }\end{array}$ \\
\hline Communication & $\begin{array}{l}\text { Being aware of how communication affects others; asking } \\
\text { questions; listening actively; showing respect in all communications, } \\
\text { oral and written; social skills. }\end{array}$ \\
\hline Teamwork & $\begin{array}{l}\text { Working well with others to complete tasks; contributing to new } \\
\text { ideas; working well with others of different gender, culture or beliefs; } \\
\text { following the directions of peers and seniors; forming positive } \\
\text { relationships; developing leadership ability. }\end{array}$ \\
\hline Self-management & $\begin{array}{l}\text { Arriving at work or class on time; wearing the right clothing and } \\
\text { having right equipment; noticing how personal words and actions } \\
\text { can affect others; showing commitment and responsibility; being } \\
\text { dependable; following instructions and completing tasks; following } \\
\text { health and safety guidelines good work habits; planning and } \\
\text { organising; showing initiative; emotional intelligence (self- } \\
\text { awareness). }\end{array}$ \\
\hline Weing willing to learn new tasks, skills and information; being curious \\
and enthusiastic about things; looking for opportunities to improve or \\
to help; accepting advice and learning from feedback.
\end{tabular}

In both the observations and the interviews, note was made as to whether the inclusion of employability skills in the teaching session were overt or covert. The research team developed an Information Sheet with the following description to clarify this distinction for our participants: 
Overt strategies are ones that the teacher designs with a specific purpose that includes the learners consciously and purposefully developing employability skills. An example might be a problem-solving task where the teacher introduces one or more staged models for learners to follow, so that they focus on the process of problem-solving, as well as the outcome. On the other hand, covert strategies are often short-term, and include strategies that have the effect of enhancing employability skills, but may be out of the awareness of both the teacher and the learner. An example might be directing the students to use shared cloud storage sites, or access web databases as part of their teamwork or research, but without drawing their attention to the digital literacy skills they are developing while completing these tasks.

Once data collection was complete, the researchers undertook a content analysis of the observation forms and transcribed interviews. Data from the observation template forms and interview transcripts were compiled according to the employability skill(s) the team deemed the best fit, as outlined in Table Two. In addition, a distinction was made between strategies to advance employability skills which were overtly displayed during the observations, that is, made explicit to the learners, or the more implicit or covert practices, still intended to promote the employability skills in learners. At times these second practices may even have been less than obvious to the teacher themselves, until reflection prompted by the researcher during the interview; the team attempted to somewhat mitigate the subjective nature of this coding through peer review.

Please note that the results reported here take account of the inclusion, and frequency, of strategies deemed to support particular skills; however no attempt has been made to compare or contrast strategies for relative efficacy. While this project is more concerned with observation and identification than with any attempt to rank pedagogic strategies, it is noted that in a time-poor, content-dense curriculum, such an issue might become the focus of subsequent inquiry.

In the data analysis, the names of participants were not linked to their organisations or to particular responses, and there was no attempt to differentiate, compare or contrast between institutions. To further ensure that interpretation was not biased due to a researcher's individual knowledge of particular participants as colleagues, multiple team members were assigned particular employability skills to search for and identify within the aggregated dataset. With the team spread across seven institutions and a wide geographic distance, cloud-based files to combine contributions, review each other's findings and select examples for the planned Guidelines resource were used. The following section reports our findings related to the frequency and implementation of the ten employability skills investigated in this study.

\section{Findings}

Incidence of the ten employability skills in the data from observation records and interview transcripts was variable. The most overtly taught skills were communication, selfmanagement, and thinking skills, with each of these evident in 18 of the 23 observed classroom sessions. The most covertly embedded skills were willingness to learn and positive attitude, which were noted in 12 sessions. The least likely to be observed were innovation and entrepreneurship. Figure 1 shows how often the ten skills were 1) evident and demonstrated overtly; or 2) were evident but covert, that is, implicitly demonstrated while embedded in the teaching and learning; or 3) were not evident, or 4) not applicable to the curriculum or level of a particular classroom session. 
Number of classroom sessions

where skill observed

20

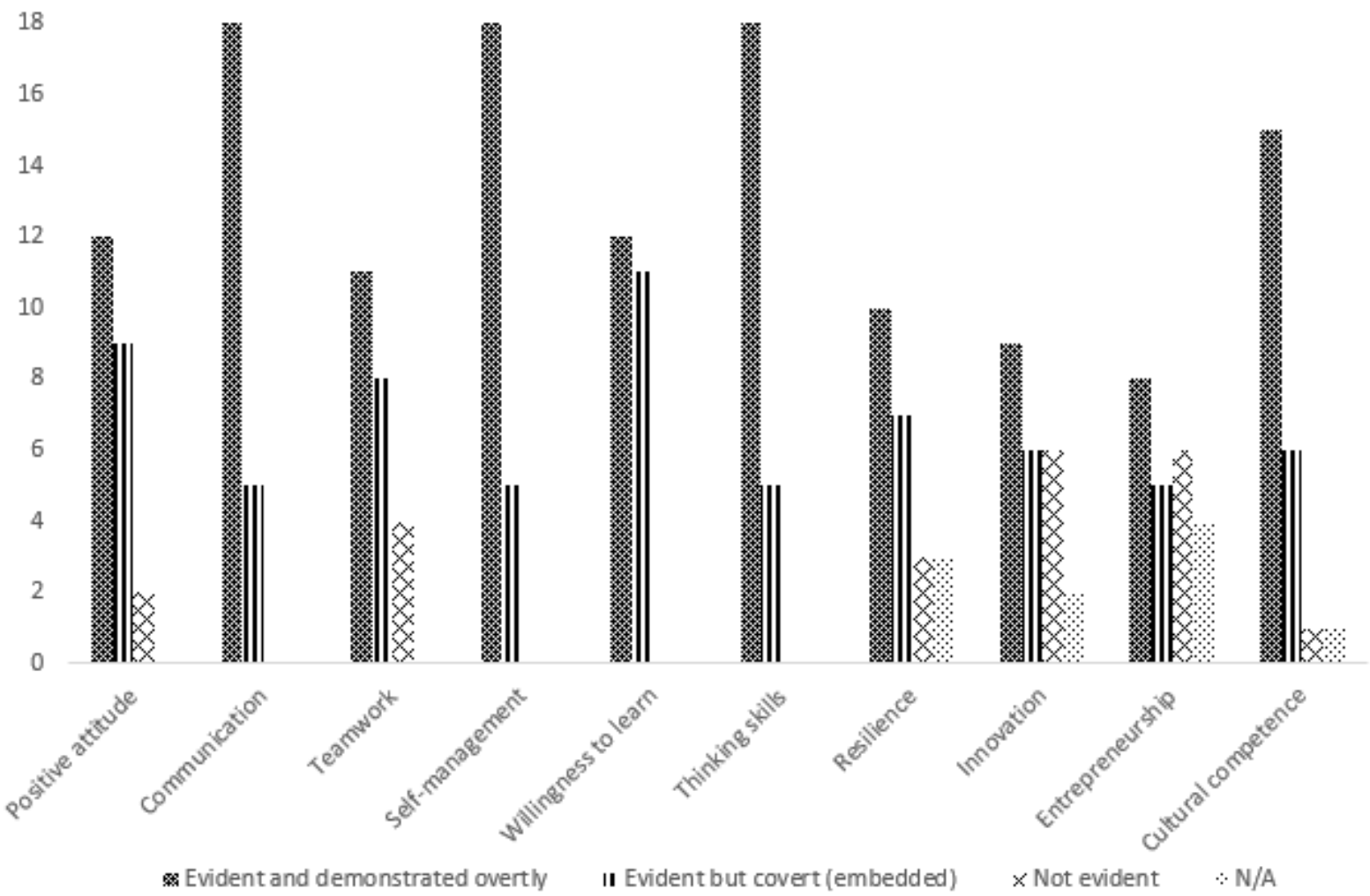

Figure 1: Employability Skills Observed as Part of a Classroom Session ( $n=23)$

In addition to the incidence of overt and covert references to employability skills observed within the 23 teaching sessions, further findings revealed the ways in which these skills were being fostered. A full account can be found in the project report for the funding agency (https://sites.google.com/view/employabilityskills). Core findings related to each of the ten skills are summarised below.

\section{Positive attitude}

Broadly, teachers were observed by researchers explicitly establishing a positive and productive learning environment, with expectations which align with industry standards. This was also evident in a classroom culture which celebrates learner progress, clarifies gaps and provides feedback and feed forward guidance.

Some examples observed and reported by researchers include:

A marks spreadsheet is maintained so students can appreciate their progress and work on the gaps.

Students are visited in practice settings three times per year, during which teachers are looking for self-belief and evidence of the learner meeting five specific dimensions of competency. These are made visible to students and if not met, goals are set to support achievement.

When prompted to describe how they implicitly foster this skill, teachers said they personally model the diverse elements of 'positive attitude' and affirm positive attitude and effort in their learners as evidenced by the following comments from respondents: 
It's about my attitude ... towards the subject, as much as the learners. What messages am I giving them to foster positive attitude, self-belief and professionalism?

I keep it friendly and accentuate the positives rather than the negatives. I keep it real.

\section{Communication}

Teachers were explicitly embedding communication skills by encouraging and responding honestly to questions, involving individuals and groups in class, modelling professionalism and authenticity. As one respondent said:

I accept any deficits and use storytelling and share personal experiences.

Some other examples reported were:

Being attentive, supportive, acknowledging identity, such as use of learner names, active listening and encouraging feedback.

Peer mentoring, group work and reporting back.

Implicit fostering of this skill included teachers demonstrating non-verbal communication, using facial expression, enthusiasm, being a good listener, demonstrating inclusive and affirmative communication. They developed relationships, and used words like 'please' and 'thank you'. Also, they managed conflicts and disagreements within teams and were assertive where necessary.

\section{Teamwork}

Teachers explicitly used exercises to generate ideas, like brainstorming and group discussion. They encouraged learners to ask and answer each other's questions and problemsolve together. One employed a class brainstorm strategy as a response to an individual's query. Teachers emphasised the value of learning from others and gaining multiple perspectives. They reinforced the concept of synergy - the whole is greater than the parts. One respondent said that he emphasises to his class:

Be collaborative. Speak up. You are really important. You could change the whole way a workplace does things.

Some examples observed and reported include:

Using structured activities done in teams, such as role plays.

Applying the Think/Pair/Share method (beginning thinking alone; sharing with peer and buddy learner; merging responses with others into group(s) and sharing with the whole class).

Strategies which were implicitly embedded this skill included reminding learners that even in individual tasks, informal collaboration and consultation can still be a part of the development process. Encouragement to see peers as a resource additional to the teacher, workbooks or online material, and to seek each other's help first before asking tutor, are also useful approaches. One respondent commented:

I highlight and notice good practice team behaviour such as turn-taking, listening and valuing others' opinions.

\section{Self-management}

In the words of one respondent: The boss expects you on time, no excuses. Explicit strategies for self-management employed by teachers in the study included developing a course structure and processes to promote self-management; for example, part of a course is selfdirected; late assignments (without approved extensions) are penalised to encourage timeliness and model 'real world' implications of late delivery of a project or job. Teachers set 
standards in the classroom to model industry standards and expectations, making these explicit; for example the use of a mind map posted on a wall with content related to positivity, consistency, sincerity, effective time management, organisation and readiness to learn.

For example one teacher was observed providing instructions to assist with time management:

Start from the top, one task at a time, then you're not running all over the problem.

Another incorporated question time into lessons, and encouraged discussion in-class about 10 minute routine changes outside class:

Who read for 10 minutes last night? Who got up 10 minutes earlier?

When prompted to describe how they implicitly foster this skill, teachers said they build selfmanagement into assessments; for example, a Time Management assessment is designed to teach prioritisation and task completion skills. One respondent said:

I redirect them when necessary, and help them to connect the need to complete the task to workplace realities or to the purpose of the activity.

\section{Willingness to learn}

With regard to this skill set, teachers were observed by researchers explicitly encouraging their learners to ask questions instead of giving them answers. They let learners see if they can work it out and/or help each other out. They allowed leaders to emerge. One respondent shared a strategy:

I ask learners to rate their personal comfort as we study a given topic, offering them three options: 'I'm OK - I'm swimming - I'm drowning' then adapt my teaching accordingly.

When prompted to describe how they implicitly foster this skill, teachers said they recognise that learners have different motivations, so try to make the environment enjoyable. Also, they use learner questions as prompts to discuss 'real world' scenarios. Many teachers shared examples from their own learning experience with learners, saying: This is how I tackled it, or This is why we are doing these tasks in class. This teacher explained that:

I take this onto myself because many international learners don't question why we are doing something. I say 'You need to be working at this speed because you won't have the opportunity to do it slowly [in industry]'.

\section{Thinking skills (problem solving and decision making)}

Members of the research team observed teachers explicitly allowing the use of the internet, industry association databases and commercial catalogues to investigate topics and find solutions. They used case studies and scenario-based learning to encourage learners to draw up solutions or make decisions; for example, a classroom or lab is set up as 'The Business Centre' with a front-of-office/ reception area and a meeting area to simulate the business workplace. The learners role-play the receptionist role and simulate a team meeting every week where they learn front-of-office and meeting management skills.

Use of project-based teaching and learning was a common strategy. In addition, the teachers used real-life situations where possible, sometimes teaching material that was not in the assessment but that learners would need in real-life employment. One example observed related to helping the learners to understand rules and regulations of a classroom, workshop, or an institution:

...learners were given policies and procedures (for example, business attire, health and safety) during simulation exercises for them to understand, reflect on and apply in practice.

When prompted to describe how they implicitly foster this skill, teachers said they focus on getting learners to think for themselves, and don't spoon-feed. One said, they'd rather be 
known as the tutor who just sits down and waits. Instead of answering a question they use prompts to help learners find the answer. Another respondent commented:

I allow learners to contribute their own strategies for solving problems, for example, throw out challenges rather than instruct.

\section{Resilience}

Resilience was fostered by teachers in the study explicitly teaching skills for managing conflict by in-depth exploration of causes and approaches to resolution. They used storytelling, sharing experiences (including the tutor's own) about when things go wrong in the workplace, and drew on others' experience too, as one respondent commented:

I encourage learners to use their own life experiences during the lesson and acknowledge when a 'good' question is asked.

Teachers consciously provide a non-bullying and safe environment for learners where a 'cando' attitude can be developed and where making mistakes is part of the learning process. In one setting, a whānau (family) group support process is in place to review assessments and construct individual action plans for learning and assessment success. Teachers adopt a 'warm-but-demanding' philosophy which helps build trust and resilience in learners, and model looking for solutions, listening and offering suggestions where appropriate. Examples reported included:

An in-class exercise where learners create a plan for acquiring a job in industry.

Modelling resilience; teachers taking responsibility for their own mistakes with humour and suggesting learners use an alternative resource to access correct information.

When prompted to describe how they implicitly foster this skill, teachers said they continue to encourage a learner who needs multiple attempts to resolve the problem by using different words, and supporting them to keep trying with patience and empathy. For example, encouraging learners having technology difficulties with software to keep working at it. One respondent said:

I do not fix the problem for the learner and instead I use the technique: What do you think? Why is that the answer? Get them to think of alternatives.

\section{Innovation}

Teachers were observed by researchers explicitly fostering innovation by using case studies from industry and business to share and showcase new ways to address issues in a discussion, prompting learners to provide alternative solutions and be creative. Some encouraged discussions of examples from around the world, not just local - how are other countries approaching these issues? What are different perspectives on this issue?

One example reported was:

This teacher personally assigns learners a mini-teaching session about a topic e.g. a social issue they have investigated, or tables a statement and has students question and discuss their assumptions: 'Doctors are the ambulance at the bottom of the cliff'. 'Plumbers help keep people healthy by creating healthy homes'.

When prompted to describe how they implicitly foster this skill, teachers said they show, not tell, the innovation message. They use a range of technologies in classroom activities - not as a feature in itself but as a tool to deliver the learning in an engaging and learner-friendly approach.

One respondent said they strive to use 'outside-the-box' analogies and associations other than what has been introduced previously; for example, television to explain colour blindness. 


\section{Entrepreneurship}

Explicit modelling of persuasiveness and salesmanship by teachers was one of the notable examples of entrepreneurship being embedded in class sessions. Teachers were active and applied solutions in practical situations, demonstrated thinking outside the square, met deadlines, and reflected other attributes, for instance, resilience, self-reflection and selfmanagement. They demonstrated knowledge of employability information, used correct terminology, made reference to stakeholders, and held career planning discussions. They prompted questions on further study and career opportunities and understood information related to literacy and numeracy skills.

Some examples observed included: modelling teamwork and decision making, leadership, and meeting deadlines; modelling roles of supervisors, setting rules and problem solving; and paying attention to individual needs, managing stressful situations, implementing peer learning, officiating groups, and having a sense of humour.

When asked to describe how they implicitly foster this skill, teachers said they demonstrate resilience in their own practice, manage stress, encourage others, recognise rules and behaviour, explain, allow mistakes, encourage questions and are active listeners. They use persuasive strategies, seek feedback, ask relevant questions, and they are organised. They role-model communication and professionalism in all interpersonal interactions.

\section{Cultural competence}

This attribute is exemplified in one respondent's statement:

I create opportunities and encourage learners to bring their voice and cultural experience to the learning space.

Diverse cultural perspectives and increased cultural awareness are part of the New Zealand landscape - in education and in the workplace. Teachers were observed by researchers explicitly validating expectations of cultural competencies for employees in both a New Zealand-wide context and an industry-specific context. Avenues here included varied teaching and learning strategies to suit a range of learning preferences, guest speakers, role play, visual resources and storytelling.

Examples of integrating tikanga Māori (Māori processes) and Māori pedagogies into teaching practice were reported, including:

Use of karakia and waiata (prayer and song); inclusion of whakawhanaungatanga (relationship building); employing poroporoaki (closure and farewell); shared kai (food); and tuakana-teina (peer teaching).

When prompted to describe how they implicitly foster this skill, teachers said they validate diverse cultural contexts, engage learners to share their personal stories and experience, and share diverse cultural stories. They use Te Reo Māori (Māori language) as a regular part of teaching practice, both for generic language associated with and relevant to teaching and learning; for example, greetings, feedback, ako (learning), korero (dialogue), mahi (work)), and for subject-specific terminology. One respondent commented:

I model cultural competence in communications, attitudes, choice of diverse learning activities and resources. I include course content that reflects cultural diversity.

\section{Discussion}

In all ten employability skill sets studied, the approach adopted by the 23 teacher-participants was one of integrating soft skill development with subject matter, as advocated by numerous commentators, including McEwen (2010) and Cranmer (2006). Explicit and deliberate, or overt links were being made by teachers between learning activities and employability, so that recognising and adopting these was a conscious act by the learners, as advocated by Green 
and Blaszczynski (2012). In addition to these overt strategies to teach employability skills, teacher-participants were able to describe additional covert strategies, with many of these related to the scaffolding approach advocated by Lievens and Wesseling (2015), the teacheras-role-model of 'embedded' behaviours (Cranmer, 2006), and the 'hidden curriculum' agenda described by Alsubaie (2015) and Bedwell et al. (2014).

Further, the data from observations and collation of respondent feedback from interviews indicated a high level of congruence with the literature in other areas. Many of the examples offered in the previous section show the four types of learning approaches which Kemmis and Hodge (2014) see as best suited for developing employability skills in context with technical skills: responsible learning; experiential learning; cooperative learning; and reflective learning. Teachers are applying creative thinking to devise activities and challenges in which employability skills are given value equivalent to that of hard skills (Gerstein \& Friedman, 2016; Simona, 2014). They are talking to their students about innovation, entrepreneurship and resilience, and the need to prepare for not only the workplace of today, but also that of tomorrow, or as Scott (2013) terms it: 'work-ready plus'.

Based on analysis of the observations and interviews carried out, and grounded in key threads identified in the literature, a key output emerging from this research is the Guidelines: Strategies for Teaching Employability Skills in Vocational Programmes online resource (https://sites.google.com/view/employabilityskills). This series of transferable strategies is intended as a contribution to colleagues across the vocational education sector, allowing teachers to explore and apply proven strategies currently being employed by good teachers (that is, those recognised in their own institutions as employing sound pedagogic principles and producing strong learner outcomes), in a variety of contexts. For example, the first of the ten skills in the Guidelines is 'Positive Attitude', and the first of six associated strategies is Establish a positive and productive learning environment which includes standards/expectations which explicitly parallel industry standards, and position learners with professionalism and integrity.

While this study offers just a small snapshot of a number of teachers and teaching sessions, many of the general ideas behind the reported practices will be transferable beyond the original context. However, it is acknowledged that data collection was limited to teachers, and what they do. Further research could consider students' perceptions of the effectiveness of explicit and implicit instruction and consciousness-raising about work-readiness skills, both before and after graduation, in first destination employment, or following their progression into higher qualifications. Feedback and review from employers would also be highly relevant and extend the value of the results reported here.

\section{Conclusion}

In an environment of rapid change - technologically, economically, socially - preparing learners for the working world has become a key priority and responsibility for vocational education providers (TEC, 2016, 2018; Whittle, Bodkin-Allen, \& Hoffman, 2015). This paper has described how a sample of experienced teachers in Aotearoa New Zealand are currently embedding ways of enhancing the employability of their students. By linking the research inquiry to international initiatives (e.g. Kinash, 2016), a wide literature about employability, work-readiness and preferred graduate attributes, and existing national skills frameworks (e.g. CareersNZ, 2017), the study reported here aims to illustrate practical strategies higher education practitioners are using to address the 'skills gap' deplored by employers and industry (Fourie \& Clokie, 2013; 2014). By garnering case studies and examples from 23 teachers across seven organisations and multiple disciplines, it is hoped that the recommendations and strategies for good practice are relevant and applicable across the sector. Hence, the Guidelines resource (https://sites.google.com/view/employabilityskills) offers authentic and transferable teaching ideas to address the development of ten industrybased, and marketable work skills: positive attitude, communication, teamwork, self- 
management, willingness to learn, thinking skills, resilience, innovation, entrepreneurship and cultural competence.

The research question which guided this inquiry was: How are teachers in Institutes of Technology and Polytechnics embedding employability skills into their teaching practices? The answer is that they are doing this both overtly and covertly, using a myriad of approaches and strategies which fit seamlessly within their delivery of core curriculum content. Further, they are creating activities and developing ideas which in most cases, are readily transferable to other contexts and subject areas.

Recounting the stories of these experienced teachers was the main objective of this project, but it is not the only positive outcome from this study. A number of future research directions have become apparent, with potential to explore in greater depth ways of teaching and embedding effective teaching practices related to building employability skills in learners - in new disciplinary settings, in different organisations, and across different qualification levels. On a practical level, ongoing discussion amongst the research team community of practice (Wenger, Trayner, \& De Laat, 2011) is scoping our possible role in creating future multimedia resources, such as videos of teachers performing an authentic practice that fosters employability. The question of how best to foster employability encompasses a wide field of endeavour as we face an unknown and unknowable world of work; we have only just begun. 


\section{References}

Alsubaie, M. A. (2015). Hidden curriculum as one of current issue of curriculum. Journal of Education and Practice 6(33), 125-128.

Bedwell, W. L., Fiore, S. M., \& Salas, E. (2014). Developing the future workforce: An approach for integrating interpersonal skills into the MBA classroom. Academy of Management Learning and Education, 13(2), 171-186. https://doi.org/10.5465/amle.2011.0138

CareersNZ / Mana Rapuara Aotearoa. (n.d.). The seven essential employability skills. Retrieved from http://www.youthguarantee.net.nz/vocational-pathways/employabilityskills/employability-skills-framework/

Chavan, R. R., \& Surve, A. Y. (2014). Assessing parameters of employability skills: An employers' perspective. Asian Journal of Management Research, 5(2), 254-260.

Cranmer, S. (2006). Enhancing graduate employability: Best intentions and mixed outcomes. Studies in Higher Education, 31(2), 169-184. https://doi.org/10.1080/03075070600572041

Fourie, E., \& Clokie, T. (2013). Recurrent themes: What communication skills do Waikato employers want from entry-level graduates? Wellington, New Zealand: 2013 New Zealand Communication Conference.

Fourie, E., \& Clokie, T. (2014). The too hard basket: Communication, graduate competence, employer expectations, and teaching the 'innate'. 26th Annual New Zealand Communication Conference.

Gerstein, M., \& Friedman, H. H. (2016). Rethinking higher education: Focusing on skills and competencies. Psychosociological Issues in Human Resource Management, 4(2), 104-121.

Green, D., \& Blaszczynski, B. (2012). Effective strategies and activities for developing soft skills, Part 1. Journal of Applied Research for Business Instruction, 10(1), 1-14.

Hendarman, A. F., \& Tjakraatmadja, J. H. (2012). Relationship among soft skills, hard skills, and innovativeness of knowledge workers in the knowledge economy era. Procedia - Social and Behavioral Sciences, 52, 35-44.

Ishak, N. M., \& Bakar, A. Y. (2013). Developing sampling frame for case study: Challenges and conditions. World Journal of Education 4(3), 1-7.

Kemmis, R. B., Hodge, S., \& Bowden, A. (2014). Transferable skills in Technical and Vocational Education and Training (TVET): Implications for TVET teacher policies in.TVET@Asia, (3), $1-13$.

Kinash, S. (n.d.). Strategies for educators to improve your students' employment outcomes. Retrieved from https://graduateemployability.com/

Kinash, S., Crane, L., Judd, M. M., \& Knight, C. (2016). Discrepant stakeholder perspectives on graduate employability strategies. Higher Education Research and Development, 35(5), 951967. https://doi.org/10.1080/07294360.2016.1139555

Lee, S., \& Benza, R. (2015). Teaching innovation skills: Application of design thinking in a graduate marketing course. Business Education Innovation Journal, (7 (June), 43-51.

Lees, B., Anderson, D., \& Avery, B. (2015). Student conceptions of employability: A phenomenographic study. In Proceedings of the 14Th European Conference on Research Methodology for Business and Management Studies (ECRM 2015) (pp. 251-258).

Lievens, R., \& E Wesseling, W. I. E. (2015). The effects of generic competences on employment outcomes. The IUP Journal of Soft Skills, 9(4), 7-25.

Lowden, K., Hall, S., Elliot, D., \& Lewin, J. (2011). Employers' perceptions of the employability skills of new graduates. London, UK, University of Glasgow SCRE Centre and Edge Foundation.

Markes, I. (2006). A review of literature on employability skill needs in engineering. European Journal of Engineering Education, 31(6), 637-650.

McEwen, B. E. (2010). Crosscultural and international career exploration and employability skills. In L. Waldman (Ed.), Crosscultural and international business education 2010 yearbook, No 48 (pp. 140-159). Reston, VA: National Business Education Association.

McLaughlin, M. (1995). Employability skills profile: What are employers looking for? ERIC Clearinghouse on Counselling and Student Services. Retrieved from https://www.ericdigests.org/1997-2/skills.htm 
Messum, D. Wilkes, L., Peters, K., \& Jackson, D. (2016). Content analysis of vacancy advertisements for employability skills: Challenges and opportunities for informing curriculum development. Journal of Teaching and Learning for Graduate Employability, 7(1), 1-15.

Ministry of Education. (n.d.). Employability skills framework. Retrieved from http://www.youthguarantee.net.nz/vocational-pathways/employability-skills/employabilityskills-framework/

Ministry of Education. (2014). Tertiary Education Strategy 2014 - 2019. Retrieved from http://www.education.govt.nz/further-education/policies-and-strategies/tertiary-educationstrategy/

Sarkar, M., Overton, T., Thompson, C., \& Rayner, G. (2016). Graduate employability: Views of recent science graduates and employers. International Journal of Innovation in Science and Mathematics Education, 24(3), 31-48.

Schneider, Z., LoBondio-Wood, G., \& Haber, J., (2003). Nursing research methods: Critical appraisal and utilisation. Sydney: Mosby Publishers.

Scott, G. (2015). Developing and assessing graduates who are work ready plus. [Keynote address to the National Tertiary Learning and Teaching conference, Tauranga: Bay of Plenty Polytechnic, 30 September - 2 October, 2015]. Available from http://ntltconference.ac.nz/

Scott, G. (2013). Improving learning and teaching quality in higher education. South African Journal of Higher Education, 27(2), 275-94.

Scott, G., Coates, H., \& Anderson, M. (2008). Learning leaders in times of change: Academic Leadership Capabilities for Australian Higher Education. Sydney: University of Western Sydney and ACER.

Shivoro, R., Shalyefu, R. K., \& Kadhila, N. (2017). Embedding graduate employability attributes in management sciences curricula: A case of two Namibian universities. Journal of Teaching and Learning for Graduate Employability, 8(1), 1-14.

Simona, G. (2015). Teacher training for embedding life skills into vocational teaching. Procedia Social and Behavioral Sciences, (180), 814-819. https://doi.org/10.1016/j.sbspro.2015.02.215

TEC (Tertiary Education Commission). (n.d.). MyQ Rate my qualification. Retrieved from https://www.myq.co.nz/

TEC (Tertiary Education Commission). (2016). Tertiary education commission framework for youth and transitions. Retrieved from www.tec.govt.nz/assets/Publications-and.../Youth-andTransition-Framework.doc

TEC (Tertiary Education Commission). (2018). ITP Roadmap 2020. Retrieved from http://www.tec.govt.nz/focus/our-focus/itp-roadmap-2020/

Wenger, E., Trayner, B., \& De Laat, M. (2011). Promoting and assessing value creation in communities and networks: A conceptual framework. Retrieved from http://wengertrayner.com/wp-content/uploads/2011/12/11-04Wenger Trayner DeLaat Value creation.pdf

Whittle, J., Bodkin-Allen, S., \& Hoffman, J. (2015). The ITP sector collaboration practices report, (April). Retrieved from https://www.sit.ac.nz/Portals/0/upload/documents/research/Collaboration Report 2015.pdf 